\title{
Efeito de Período de Controle de Plantas Daninhas na Cultura DE AMENDOIM ${ }^{1}$
}

\author{
Effects of Weed Control Periods on Peanut Crop
}

PITELLI, R.A. ${ }^{2}$, GAVIOLI, V.D. ${ }^{3}$, GRAVENA, R. ${ }^{4}$ e ROSSI, C.A. ${ }^{3}$

\begin{abstract}
RESUMO - Dois experimentos foram conduzidos com o objetivo de avaliar os efeitos de diferentes períodos de controle das plantas daninhas, sobre algumas características produtivas da cultura do amendoim. Os experimentos foram instalados no município de Taquaritinga-SP, em duas épocas de semeadura, sendo uma no cultivo "das secas", semeada durante o mês de março, e outra no cultivo "das águas", semeada durante o mês de setembro. Os tratamentos foram períodos de controle das plantas daninhas entre 0-17, 0-31, 0-45, 0-59, 0-73, 17-31, 17-45, 17-59, 17-73, 31-45, 31-59, 31-73, 45-59, 45-73 e 59-73 dias após a emergência da cultura. Foram mantidas duas testemunhas, uma sem controle e outra com controle das plantas daninhas durante todo o ciclo da cultura. A principal planta daninha, nos dois experimentos, foi Digitaria horizontalis. A comunidade infestante e a cultura foram influenciadas pela época de semeadura, modificando suas relações de interferência. No cultivo da época "das águas", os efeitos da convivência da comunidade infestante foram mais drásticos, afetando com maior intensidade a produtividade da cultura. Dentre as características produtivas avaliadas, o número de vagens por planta foi o principal fator na redução da produtividade. No cultivo "das águas", o controle somente foi necessário após os 45 dias iniciais de convivência, e na cultura "das secas", após os 59 dias, caracterizando os períodos anteriores à interferência. Nas duas épocas de semeadura o controle das plantas daninhas, realizado até 17 dias após a emergência, foi suficiente para garantir a produtividade da cultura semelhante à testemunha capina, caracterizando o período total de prevenção à interferência.
\end{abstract}

Palavras-chave: Digitaria horizontalis, competição, interferência.

ABSTRACT - Field trials were carried out to study the effect of weed control periods on some yield components of the peanut crop. Two experiments were carried out in Taquaritinga-SP, Brazil, one during the "dry season" (seeds sown in March), and the other during the "rainy season" (seeds sown in September). The treatments utilized were the following weed control periods: 0-17, 0-31, 0-45, 0-59, 0-73, 17-31, 17-45, 17-59, 17-73, 31-45, 31-59, 31-73, 45-59, 45-73 and 59-73 days after plant emergence. Two controls were used, one without weed control, and the other without weed interference during throughout the crop cycle. The major weed infesting both trials was Digitaria horizontalis. The infesting weed community and crop were affected by the seeding season, altering their interference relationships. In the "rainy season", the effects of the infesting weed community were more drastic, affecting peanut yield more intensely. Among the yield crop components evaluated, the number of pods per plant was the major factor in yield reduction. In the "rainy season", control was needed only after 45 days of weed interference while in the dry season, only after 59 days, characterizing the critical times prior to interference. In both seeding seasons, weed control carried out up to 17 days after emergence was enough to maintain yield crop, being characterized as the critical weed-free period.

Key words: Digitaria horizontalis, competition, interference.

Recebido para publicação em 7/8/2001 e na forma revisada em 9/12/2002.

2 Prof. Titular do Dep. de Biologia Aplicada à Agropecuária da FCAV/UNESP, Via Prof. Paulo D. Castellane, s/n, 14870-000 Jaboticabal-SP; ${ }^{3}$ Eng.-Agr.; ${ }^{4}$ Eng.-Agr., Pós-graduando do curso de Fitotecnia da ESALQ/USP, Av. Pádua Dias, 11, 14418-900 Piracicaba-SP.

Planta Daninha, Viçosa-MG, v.20, n.3, p.389-397, 2002 


\section{INTRODUÇÃO}

O grau de interferência entre as plantas cultivadas e as plantas daninhas depende de diversos fatores relacionados à comunidade infestante (composição específica, densidade e distribuição) e à própria cultura (gênero, espécie ou cultivar, espaçamento entre sulcos e densidade de semeadura). Além disso, depende também da época e duração do período de convivência mútua, sendo modificado pelas condições edáficas e climáticas e pelos tratos culturais (Pitelli, 1985).

$\mathrm{Na}$ cultura do amendoim, a influência de quase todos esses fatores já foi passivel de estudo. O aumento da densidade de plantas daninhas proporciona maior competição com a cultura (Chamblee et al., 1982; Royal et al., 1997) e a composição específica tem grande influência no grau de competição da comunidade infestante (Buchanan et al., 1976; Royal et al., 1997). Verificou-se que cultivares de porte ereto geralmente são menos suscetiveis à matocompetição que cultivares prostrados (Feakin, 1973) e que menor espaçamento pode proporcionar maior competitividade à cultura (Martins \& Pitelli, 1994). Relações competitivas entre o amendoim e as plantas daninhas podem ainda ser influenciadas pelas práticas culturais empregadas no cultivo (Feakin, 1973; Buchanan et al., 1976; Bianco, 1978) e pelas condições climáticas (Feakin, 1973).

Com relação aos efeitos de diferentes períodos de controle de convivência sobre a interferência das plantas daninhas na cultura do amendoim, muitos estudos já foram realizados e os resultados têm sido distintos. Essas variações podem ser explicadas pela atuação dos diferentes fatores que afetam as relações de interferência entre as plantas daninhas e as culturas (Feakin, 1973; Buchanan et al., 1976; Martins \& Pitelli, 1994).

Resultados obtidos no Brasil demonstram que o período total de prevenção à interferência (PTPI) tem variado entre uma e três semanas (Pacheco, 1980; Pitelli et al., 1981; Barbosa \& Pitelli, 1990; Martins \& Pitelli, 1994; Kasai et al., 1997) e o período anterior à interferência (PAI), entre oito e dez semanas (Pitelli et al., 1981; Pitelli et al., 1984; Barbosa \& Pitelli, 1990; Kasai et al., 1997).

Planta Daninha, Viçosa-MG, v.20, n.3, p.389-397, 2002
O objetivo deste trabalho foi estudar, em duas épocas de plantio, os efeitos de diferentes épocas e extensões do período de controle das plantas daninhas sobre a produtividade e qualidade dos grãos de amendoim. A relevância do presente trabalho está no esquema dos tratamentos de controle das plantas daninhas, que é diverso do método aditivo de tempo normalmente empregado.

\section{MATERIAL E MÉTODOS}

Os experimentos foram conduzidos no município de Taquaritinga-SP, num solo com horizonte A de textura arenosa, classificado como Argissolo. A análise da amostra de solo, coletada antes da instalação dos experimentos, apresentou as seguintes características químicas: $\mathrm{pH}$ em $\mathrm{CaCl}_{2}$ de 5,3; $8 \mathrm{~g} \mathrm{dm}^{-3}$ de matéria orgânica; $3 \mathrm{mg} \mathrm{dm}^{-3}$ de P resina; $\mathrm{V}$ de $59 \%$; e teores de $\mathrm{K}, \mathrm{Ca}, \mathrm{Mg}, \mathrm{H}+\mathrm{Al}$ e $\mathrm{S}$ de 1,$9 ; 14,5 ; 6,4$; 16,0 ; e $22,8 \mathrm{mmol} \mathrm{dm}^{-3}$, respectivamente. O preparo do solo foi efetuado no sistema convencional, com uma aração e duas gradagens.

O cultivar de amendoim Tatu-53 foi semeado em março para o ciclo "das secas" e em setembro para o ciclo "das águas". A adubação de plantio constou da aplicação de $300 \mathrm{~kg} \mathrm{ha}^{-1}$ da fórmula 04-14-08 (N-P-K). O espaçamento entre sulcos foi de $60 \mathrm{~cm}$, com aproximadamente 18 sementes por metro de sulco. Durante o ciclo da cultura, para as duas épocas de plantio, foram realizadas três aplicações de inseticidas organofosforados, visando o controle de pragas.

Os experimentos foram locados de acordo com o delineamento experimental de blocos casualizados, com quatro repetições no ciclo "das secas" e três no ciclo "das águas". As parcelas experimentais foram constituídas de cinco linhas de semeadura com $5 \mathrm{~m}$ de comprimento, perfazendo uma área total de $15 \mathrm{~m}^{2}$. Como área útil foram consideradas as três linhas centrais, desprezando-se $0,5 \mathrm{~m}$ nas extremidades, perfazendo $7,2 \mathrm{~m}^{2}$.

Os tratamentos experimentais foram constituídos por períodos de controle das plantas daninhas entre 0-17, 0-31, 0-45, 0-59, 0-73, 1731, 17-45, 17-59, 17-73, 31-45, 31-59, 31-73, 45-59, 45-73 e 59-73 dias após a emergência da cultura. Foram mantidas duas testemunhas, uma sem controle e outra com controle das 
plantas daninhas durante todo o ciclo da cultura. O controle das plantas daninhas foi realizado por capinas, numa freqüência de três a quatro dias.

Nos tratamentos em que houve um período inicial de controle, partindo da emergência do amendoim, e na testemunha no mato, a avaliação da comunidade infestante foi efetuada na colheita da cultura. Nos demais tratamentos, a avaliação foi efetuada no início dos períodos de controle da comunidade infestante. Foram avaliadas duas amostras de $0,25 \mathrm{~m}^{2}$, por parcela, sendo determinados a composição específica da comunidade infestante, o número de indivíduos e a biomassa seca acumulada pelas diferentes populações.

As operações de colheita foram realizadas aos 104 e 101 dias após o plantio da cultura do amendoim, nos ciclos "das secas" e "das águas", respectivamente. Foram avaliados o estande, a porcentagem da massa de grãos na massa das vagens, a massa média de 100 grãos, a distribuição porcentual dos grãos nos vários diâmetros das malhas de peneira utilizadas nas classificações comerciais (peneiras 24, 22, 20, 18 e 16), o número de vagens por planta e a produtividade em vagens.

Os resultados foram submetidos à análise de variância pelo teste $\mathrm{F}$ e, posteriormente, ao teste de Tukey, para comparação de médias.

\section{RESULTADOS E DISCUSSÃO}

As espécies de plantas daninhas encontradas no experimento "das secas" foram Amaranthus spp., Bidens pilosa, Cenchrus echinatus, Commelina benghalensis, Digitaria horizontalis, Eleusine indica, Portulaca oleracea e Sida spp. No ciclo "das águas" foram B. pilosa, Brachiaria plantaginea, C. echinatus, C. benghalensis, Dactyloctenium aegyptium, D. horizontalis, E. indica, Rhynchelitrum repens e Sida spp.

Nos dois experimentos, a espécie predominante na comunidade infestante foi o capimcolchão (Digitaria horizontalis), representando mais de 58\% dos indivíduos encontrados nas avaliações e mais de $41 \%$ da biomassa seca acumulada pela comunidade infestante (Tabelas 1 e 2).

Pitelli (1980), numa pesquisa bibliográfica sobre trabalhos publicados que abordavam plantas daninhas na cultura de amendoim, constatou que Digitaria sanguinalis. foi a espécie mais freqüentemente citada. É importante considerar que, pelas semelhanças morfológicas existentes entre as espécies, é possivel que, em muitas ocasiões, a espécie presente fosse $D$. horizontalis. Lorenzi (1991) afirma que D. sanguinalis ocorre com pequena freqüência no Brasil, quase exclusivamente no extremo sul do País. D. horizontalis é citada como sendo predominante na Região Sudeste (Kissmann, 1997).

Nas duas épocas de plantio, as densidades de indivíduos das comunidades infestantes e de Digitaria horizontalis, encontradas na testemunha mantida no mato, não diferiram dos tratamentos em que a capina foi iniciada aos 17 dias após a emergência da cultura (DAE) (Tabelas 1 e 2). Esses resultados indicam que, nas duas épocas de plantio, aos 17 dias, praticamente todos os componentes da comunidade infestante já haviam emergido e estavam estabelecidos no ambiente. Essa constatação é confirmada pelos resultados obtidos quando o controle foi iniciado na emergência e estendido até 17 dias, quando, posteriormente, poucos indivíduos foram encontrados no tratamento (Tabelas 1 e 2). Quando as capinas se estenderam até os 31 dias ou acima, nenhum indivíduo foi encontrado nas parcelas experimentais. Esses resultados podem ser em decorrência da redução nas precipitações após os 17 dias (Figura 1) e da interferência proporcionada pela cultura, impedindo o estabelecimento das plantas daninhas emergentes.

Bhan et al. (1971) verificaram que $75 \%$ dos componentes das comunidades infestantes da cultura do amendoim podem emergir nos primeiros 30 dias do ciclo da cultura. Pitelli et al. (1981) observaram que, aos 30 dias, em termos de número de indivíduos, uma comunidade infestante da cultura do amendoim "das águas" encontrava-se implantada. Na cultura "das secas", Pitelli et al. (1984) constataram que essa implantação já havia ocorrido aos 14 dias.

Destaca-se a maior incidência de indivíduos na cultura "das secas". Pode ser considerado como possível explicação o fato de que antes da cultura "das secas" foi conduzida uma cultura de arroz de sequeiro e, tão logo processada a colheita, os restos culturais e de plantas daninhas (incluindo seus propágulos) foram 
Tabela 1 - Número de indivíduos e biomassa seca acumulada pela comunidade infestante e por Digitaria horizontalis no experimento conduzido no período "das secas"

\begin{tabular}{|c|c|c|c|c|c|c|}
\hline \multirow{3}{*}{$\begin{array}{l}\text { Período de controle das } \\
\text { plantas daninhas (dias) }\end{array}$} & \multicolumn{3}{|c|}{ Comunidade Infestante } & \multicolumn{3}{|c|}{ Digitaria horizontalis } \\
\hline & \multicolumn{2}{|c|}{$\begin{array}{c}\text { Densidade } \\
\text { (indivíduos } 0,5 \mathrm{~m}^{-2} \text { ) }\end{array}$} & \multirow{2}{*}{$\begin{array}{l}\text { Biomassa seca } \\
(\mathrm{g})\end{array}$} & \multicolumn{2}{|c|}{$\begin{array}{c}\text { Densidade } \\
\text { (indivíduos } 0,5 \mathrm{~m}^{-2} \text { ) }\end{array}$} & \multirow{2}{*}{$\begin{array}{c}\text { Biomassa seca } \\
(\mathrm{g})\end{array}$} \\
\hline & D. O. ${ }^{1 /}$ & Transf. $\stackrel{2}{ }$ & & D. O. & Transf. & \\
\hline $00 \quad \underline{3} /$ & 110,25 & $10,22 \mathrm{AB}$ & $45,56 \mathrm{~A}$ & 110,00 & $10,21 \mathrm{ABC}$ & $45,50 \mathrm{~A}$ \\
\hline $00-17^{\underline{3} /}$ & 28,50 & $5,25 \mathrm{BC}$ & $2,79 \mathrm{C}$ & 28,50 & $5,25 \mathrm{CD}$ & $2,79 \mathrm{~B}$ \\
\hline $00-31^{\underline{3} /}$ & 0,00 & $0,71 \mathrm{C}$ & $0,00 \mathrm{C}$ & 0,00 & $0,71 \mathrm{D}$ & $0,00 \mathrm{~B}$ \\
\hline $00-45^{\underline{3} /}$ & 0,00 & $0,71 \mathrm{C}$ & $0,00 \mathrm{C}$ & 0,00 & $0,71 \mathrm{D}$ & $0,00 \mathrm{~B}$ \\
\hline $00-59 \stackrel{3}{\prime}$ & 0,00 & $0,71 \mathrm{C}$ & $0,00 \mathrm{C}$ & 0,00 & $0,71 \mathrm{D}$ & $0,00 \mathrm{~B}$ \\
\hline $00-73^{\underline{3} /}$ & 0,00 & $0,71 \mathrm{C}$ & $0,00 \mathrm{C}$ & 0,00 & $0,71 \mathrm{D}$ & $0,00 \mathrm{~B}$ \\
\hline $17-31^{4}$ & 107,25 & $10,28 \mathrm{AB}$ & $2,49 \mathrm{C}$ & 62,25 & $7,83 \mathrm{BC}$ & $1,01 \mathrm{~B}$ \\
\hline $17-45^{4 /}$ & 106,75 & $10,27 \mathrm{AB}$ & $2,18 \mathrm{C}$ & 84,75 & $9,12 \mathrm{ABC}$ & $1,74 \mathrm{~B}$ \\
\hline $17-59^{4 /}$ & 119,25 & $10,83 \mathrm{~A}$ & $2,39 \mathrm{C}$ & 93,00 & $9,34 \mathrm{ABC}$ & $1,64 \mathrm{~B}$ \\
\hline $17-73^{4} \prime$ & 132,00 & $11,32 \mathrm{~A}$ & $2,09 \mathrm{C}$ & 107,00 & $10,11 \mathrm{ABC}$ & $1,59 \mathrm{~B}$ \\
\hline $31-45^{4 \prime}$ & 195,25 & $13,93 \mathrm{~A}$ & $7,79 \mathrm{C}$ & 155,50 & $12,43 \mathrm{AB}$ & $7,25 \mathrm{~B}$ \\
\hline $31-59 \stackrel{4}{\prime}$ & 155,75 & $12,08 \mathrm{~A}$ & $7,30 \mathrm{C}$ & 145,50 & $11,60 \mathrm{AB}$ & $6,57 \mathrm{~B}$ \\
\hline $31-73^{4 /}$ & 224,50 & $14,94 \mathrm{~A}$ & $11,22 \mathrm{BC}$ & 198,25 & $14,02 \mathrm{~A}$ & $8,79 \mathrm{~B}$ \\
\hline $45-59^{4} \prime$ & 149,50 & $12,21 \mathrm{~A}$ & $27,44 \mathrm{ABC}$ & 129,25 & $11,36 \mathrm{Ab}$ & $22,76 \mathrm{AB}$ \\
\hline $45-73^{4 \prime}$ & 204,50 & $13,95 \mathrm{~A}$ & $29,36 \mathrm{ABC}$ & 200,50 & $13,75 \mathrm{~A}$ & $27,70 \mathrm{AB}$ \\
\hline $59-73^{4 /}$ & 128,25 & $11,41 \mathrm{~A}$ & $40,93 \mathrm{AB}$ & 126,00 & $11,06 \mathrm{AB}$ & $37,94 \mathrm{~A}$ \\
\hline $\mathrm{F}$ tratamentos & & $25,84 * *$ & $6,94 * *$ & & $19,73 * *$ & $7,35 * *$ \\
\hline F blocos & & $0,15^{\text {ns }}$ & $0,47^{\mathrm{ns}}$ & & $0,24^{\mathrm{ns}}$ & $0,33^{\mathrm{ns}}$ \\
\hline $\mathrm{CV}(\%)$ & & 23,63 & 103,31 & & 27,19 & 105,59 \\
\hline d. m. s. & & 5,27 & 30,04 & & 5,62 & 27,07 \\
\hline
\end{tabular}

${ }^{1 /}$ Dados originais. ${ }^{2 /}$ Transformação em raiz de $(\mathrm{x}+0,5) .{ }^{3 /}$ Avaliações efetuadas no final do ciclo da cultura. ${ }^{4 /}$ Avaliações efetuadas por ocasião do início do período de controle das plantas daninhas.

${ }^{\text {ns }}$ Não-significativo. ${ }^{* *}$ Significativo a $1 \%$ de probabilidade. Médias acompanhadas de mesma letra não diferem estatisticamente entre si (Tukey, 5\%).

incorporados ao solo, que foi imediatamente preparado para a instalação do experimento. No local em que foi instalado o experimento com a cultura "das águas", o arroz de sequeiro foi colhido em fevereiro e os restos culturais e plantas daninhas foram incorporados bem mais tarde, dando oportunidade para que grande parte dos propágulos germinasse e suas plantas fossem destruídas nas operações que se seguiram no preparo do solo.

Analisando os valores observados para a biomassa seca acumulada pela comunidade infestante nas testemunhas mantidas no mato (Tabelas 1 e 2), pode ser constatado que, embora o número de indivíduos na cultura "das secas" fosse aproximadamente três vezes maior que o observado na cultura "das águas", o acúmulo de biomassa seca foi quase oito vezes menor. Esse fato pode ser parcialmente expli- cado pela maior precipitação ocorrida no ciclo da cultura "das águas", que foi de 392,8 mm, contra 163,5 mm da cultura "das secas" (Figura 1).

Na Tabela 3 estão apresentados os valores de biomassa seca acumulada pelas comunidades infestantes em diferentes períodos, considerando o acúmulo em valores absolutos e relativos, e as precipitações e temperaturas médias nos períodos considerados. $\mathrm{O}$ acúmulo de biomassa seca, em valores absolutos, foi sempre maior na cultura "das águas". No entanto, a precipitação entre 17 e 59 dias foi maior na cultura "das secas", indicando que, até 59 dias, o fator limitante do desenvolvimento da comunidade infestante na cultura "das secas" não deve ter sido a precipitação. É provável que a ocorrência de temperaturas médias inferiores na época das secas tenha 
contribuído para o menor desenvolvimento da comunidade infestante (Tabela 3). Também deve ser considerado que, na cultura "das secas", as plantas de Digitaria horizontalis, que dominavam amplamente a comunidade infestante, floresceram precocemente, quando ainda apresentavam pequeno desenvolvimento vegetativo, e, a partir daí, seu incremento de biomassa seca foi muito pequeno. A explicação para esse fato reside numa possível suscetibilidade da planta ao fotoperíodo, que ia paulatinamente tornando-se mais curto.

Considerando a biomassa seca acumulada em valores relativos à testemunha no mato (Tabela 3), aos 59 dias a comunidade infestante da cultura "das secas" havia acumulado perto de $90 \%$ de sua biomassa seca final, enquanto para a comunidade infestante da cultura "das águas” esse valor esteve em torno de $44 \%$. No caso da cultura "das secas" não ocorreu precipitação após 59 dias, o que pode ter prejudicado o acúmulo de biomassa seca. Para a cultura “das águas", nessa época, havia chovido apenas $38,2 \%$ da precipitação total verificada no ciclo.

A presença das plantas daninhas não alterou significativamente o índice de mortalidade das plantas de amendoim e a porcentagem de massa dos grãos na massa da vagem (Tabelas 4 e 5). Bianco (1978), Pitelli et al. (1981), Pitelli et al. (1984) e Barbosa \& Pitelli (1990) também não observaram efeitos significativos da presença da comunidade infestante sobre o estande da cultura. Bianco (1978) pondera que a interferência das plantas daninhas altera em maior proporção a produtividade por indivíduo do que a própria sobrevivência das plantas de amendoim. Pitelli (1980) e Pitelli et al. (1984) não constataram efeitos da interferência das

Tabela 2 - Número de indivíduos e biomassa seca acumulada pela comunidade infestante e por Digitaria horizontalis no experimento conduzido no período "das águas"

\begin{tabular}{|c|c|c|c|c|c|c|}
\hline \multirow{3}{*}{$\begin{array}{l}\text { Período de controle das } \\
\text { plantas daninhas (dias) }\end{array}$} & \multicolumn{3}{|c|}{ Comunidade Infestante } & \multicolumn{3}{|c|}{ Digitaria horizontalis } \\
\hline & \multicolumn{2}{|c|}{$\begin{array}{c}\text { Densidade } \\
\text { (indivíduos } 0,5 \mathrm{~m}^{-2} \text { ) }\end{array}$} & \multirow{2}{*}{$\begin{array}{l}\text { Biomassa seca } \\
(\mathrm{g})\end{array}$} & \multicolumn{2}{|c|}{$\begin{array}{c}\text { Densidade } \\
\text { (indivíduos } 0,5 \mathrm{~m}^{-2} \text { ) }\end{array}$} & \multirow{2}{*}{$\begin{array}{c}\text { Biomassa seca } \\
(\mathrm{g})\end{array}$} \\
\hline & D. O. ${ }^{1 /}$ & Transf. $\stackrel{2}{ }=$ & & D. O. & Transf. & \\
\hline $00 \quad \underline{3} /$ & 35,67 & $6,01 \mathrm{~A}$ & $367,10 \mathrm{~A}$ & 32,67 & $5,75 \mathrm{AB}$ & $338,97 \mathrm{~A}$ \\
\hline $00-17^{\stackrel{3}{3} /}$ & 10,00 & $3,23 \mathrm{BC}$ & $1,99 \mathrm{D}$ & 6,66 & $2,62 \mathrm{BC}$ & $1,46 \mathrm{D}$ \\
\hline $00-31^{\stackrel{3}{3}}$ & 0,00 & $0,71 \mathrm{C}$ & $0,00 \mathrm{D}$ & 0,00 & $0,71 \mathrm{C}$ & $0,00 \mathrm{D}$ \\
\hline $00-45^{\underline{3} /}$ & 0,00 & $0,71 \mathrm{C}$ & $0,00 \mathrm{D}$ & 0,00 & $0,71 \mathrm{C}$ & $0,00 \mathrm{D}$ \\
\hline $00-59^{\underline{3} /}$ & 0,00 & $0,71 \mathrm{C}$ & $0,00 \mathrm{D}$ & 0,00 & $0,71 \mathrm{C}$ & $0,00 \mathrm{D}$ \\
\hline $00-73^{3 /}$ & 0,00 & $0,71 \mathrm{C}$ & $0,00 \mathrm{D}$ & 0,00 & $0,71 \mathrm{C}$ & $0,00 \mathrm{D}$ \\
\hline $17-31^{4 /}$ & 28,67 & $5,30 \mathrm{AB}$ & $3,20 \mathrm{D}$ & 24,00 & $4,84 \mathrm{AB}$ & $2,67 \mathrm{D}$ \\
\hline $17-45^{4 /}$ & 30,67 & $5,45 \mathrm{AB}$ & $3,47 \mathrm{D}$ & 28,00 & $5,21 \mathrm{AB}$ & $3,11 \mathrm{D}$ \\
\hline $17-59^{4 /}$ & 32,00 & $5,65 \mathrm{AB}$ & $3,92 \mathrm{D}$ & 28,00 & $5,27 \mathrm{AB}$ & $3,35 \mathrm{D}$ \\
\hline $17-73^{4 /}$ & 29,33 & $5,38 \mathrm{AB}$ & $2,86 \mathrm{D}$ & 22,33 & $4,55 \mathrm{ABC}$ & $1,90 \mathrm{D}$ \\
\hline $31-45^{4 /}$ & 35,00 & $5,82 \mathrm{AB}$ & $19,18 \mathrm{D}$ & 30,00 & $5,28 \mathrm{AB}$ & $13,40 \mathrm{CD}$ \\
\hline $31-59 \stackrel{4}{\prime}$ & 40,33 & $6,33 \mathrm{~A}$ & $18,32 \mathrm{D}$ & 28,00 & $4,55 \mathrm{ABC}$ & $10,55 \mathrm{CD}$ \\
\hline $31-73^{4 /}$ & 35,33 & $5,98 \mathrm{~A}$ & $18,51 \mathrm{D}$ & 23,67 & $4,79 \mathrm{ABC}$ & $9,84 \mathrm{CD}$ \\
\hline $45-59^{4}$ & 54,00 & $7,33 \mathrm{~A}$ & $54,86 \mathrm{C}$ & 49,33 & $7,00 \mathrm{~A}$ & $51,66 \mathrm{C}$ \\
\hline $45-73^{4 /}$ & 55,00 & $7,44 \mathrm{~A}$ & $62,06 \mathrm{C}$ & 51,33 & 7,19 A & $53,13 \mathrm{C}$ \\
\hline $59-73^{4 /}$ & 35,67 & $5,97 \mathrm{~A}$ & $160,80 \mathrm{~B}$ & 29,67 & $5,42 \mathrm{AB}$ & $112,36 \mathrm{~B}$ \\
\hline F tratamentos & & $25,17 * *$ & $245,81 * *$ & & $8,30 * *$ & $104,49 * *$ \\
\hline F blocos & & $1,47^{\mathrm{ns}}$ & $1,14^{\mathrm{ns}}$ & & $0,55^{\mathrm{ns}}$ & $0,20^{\mathrm{ns}}$ \\
\hline $\mathrm{CV}(\%)$ & & 18,72 & 23,55 & & 33,17 & 38,67 \\
\hline d. m.s. & $-\ldots$ & 2,59 & 32,07 & $-\ldots$ & 4,12 & 44,13 \\
\hline
\end{tabular}

$1 /$ Dados originais. ${ }^{2 /}$ Transformação em raiz de $(x+0,5) .{ }^{3 /}$ Avaliações efetuadas no final do ciclo da cultura. ${ }^{4 /}$ Avaliações efetuadas por ocasião do início do período de controle das plantas daninhas.

${ }^{\text {ns }}$ Não-significativo. ${ }^{* *}$ Significativo a $1 \%$ de probabilidade. Médias acompanhadas de mesma letra não diferem estatisticamente entre si (Tukey, 5\%). 


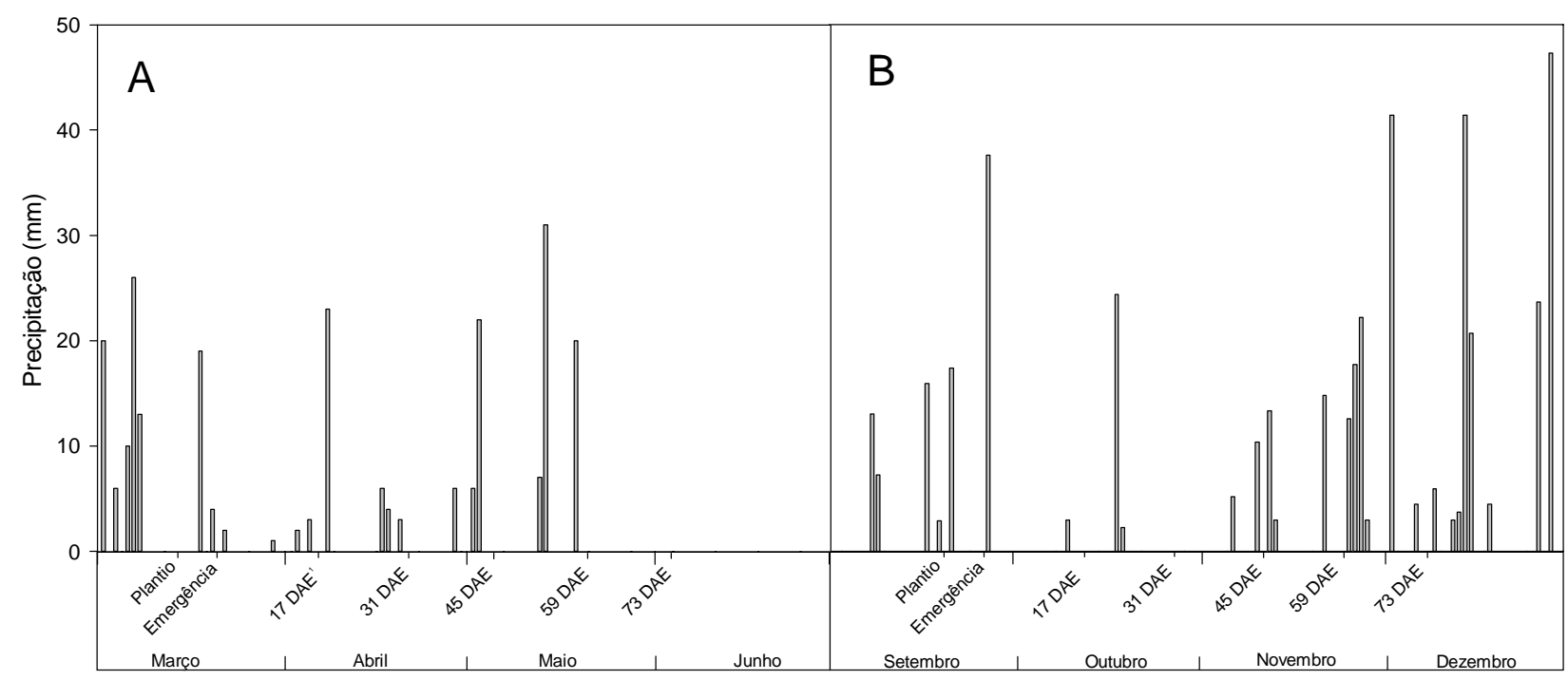

Figura 1 - Precipitações diárias ocorridas nos meses em foram conduzidos os experimentos dos ciclos "das secas" (A) e "das águas”(B). 'DAE - dias após a emergência.

Tabela 3 - Acúmulos médios de biomassa seca pelas comunidades infestantes, em valores absolutos e relativos à testemunha no mato, precipitações pluviométricas totais e temperaturas médias do ar nos períodos considerados

\begin{tabular}{|c|c|c|c|c|c|c|c|c|c|}
\hline \multirow{3}{*}{$\begin{array}{l}\text { Período } \\
\text { (dias) }\end{array}$} & \multirow{3}{*}{ Cultura } & \multicolumn{4}{|c|}{ Acúmulo de biomassa seca } & \multirow{2}{*}{\multicolumn{2}{|c|}{ Precipitação (mm) }} & \multirow{2}{*}{\multicolumn{2}{|c|}{ Temperatura média }} \\
\hline & & \multicolumn{2}{|c|}{ No Período } & \multicolumn{2}{|c|}{ Acumulado $^{-2 /}$} & & & & \\
\hline & & $\begin{array}{l}\text { Absoluto } \\
(\mathrm{g})\end{array}$ & $\begin{array}{c}\text { Relativo }^{1 /} \\
(\%)\end{array}$ & $\begin{array}{l}\text { Absoluto } \\
(\mathrm{g})\end{array}$ & $\begin{array}{c}\text { Relativo }^{1 /} \\
(\%)\end{array}$ & $\begin{array}{c}\text { No } \\
\text { Período }\end{array}$ & $\begin{array}{l}\text { Acumu- } \\
\text { lado }\end{array}$ & $\begin{array}{c}\text { No } \\
\text { Período }\end{array}$ & $\mathrm{GFPC}^{3 /}$ \\
\hline \multirow{2}{*}{$0-17$} & águas & 3,31 & 0,90 & 3,31 & 0,90 & 58,8 & 58,8 & 24,7 & 24,7 \\
\hline & secas & 2,29 & 5,03 & 2,29 & 5,03 & 29,6 & 29,6 & 26,0 & 26,0 \\
\hline \multirow{2}{*}{$17-31$} & águas & 15,36 & 4,18 & 18,67 & 5,09 & 29,7 & 88,4 & 26,8 & 25,7 \\
\hline & secas & 6,48 & 14,22 & 8,77 & 19,25 & 35,8 & 65,4 & 24,3 & 25,2 \\
\hline \multirow{2}{*}{$31-45$} & águas & 39,79 & 10,84 & 58,46 & 15,92 & 14,0 & 102,4 & 30,0 & 27,0 \\
\hline & secas & 19,63 & 43,09 & 28,40 & 62,34 & 36,7 & 102,1 & 22,3 & 24,5 \\
\hline \multirow{2}{*}{$45-59$} & águas & 102,34 & 27,88 & 160,80 & 43,80 & 47,7 & 150,1 & 24,5 & 26,4 \\
\hline & secas & 12,53 & 27,50 & 40,93 & 89,84 & 61,4 & 163,5 & 24,0 & 24,4 \\
\hline
\end{tabular}

${ }^{1 /}$ Em relação à biomassa seca acumulada na testemunha no mato. ${ }^{2 /}$ Acumulado até o final do período considerado. ${ }^{3 /}$ Temperatura média do período abrangido da germinação até o final do período considerado.

plantas daninhas sobre a porcentagem de casca. Outros autores, em outras condições, observaram efeitos negativos dessa interferência na manifestação da característica (Bianco, 1978; Buchanan et al., 1976). Bianco (1978) observa que o decréscimo na porcentagem de casca não é simplesmente o reflexo do inverso do crescimento das sementes no seu interior, mas que a própria casca é afetada em sua formação.

Em se tratando da massa média de 100 grãos, somente foram constatados efeitos significativos dos tratamentos na cultura "das águas” (Tabelas 4 e 5). No entanto, não houve redução de qualquer tratamento em relação à testemunha no limpo. Esse resultado fez com que não ocorressem diferenças significativas na distribuição percentual dos grãos nos vários diâmetros das malhas de peneira utilizadas nas classificações comerciais. Dajoz (1983) afirma que, geralmente, a competição entre plantas acarreta diminuição da massa individual da planta e no número de sementes formadas, porém a massa de cada semente tende a 
Tabela 4 - Efeitos do período de controle das plantas daninhas sobre o número de plantas na colheita, a porcentagem da massa do grão na vagem, a massa média de 100 grãos, o número de vagens por planta e a produtividade de vagens do amendoim "das secas"

\begin{tabular}{|c|c|c|c|c|c|c|c|}
\hline \multirow{2}{*}{$\begin{array}{l}\text { Período de con- } \\
\text { trole de mato } \\
\quad \text { (dias) }\end{array}$} & \multicolumn{2}{|c|}{$\begin{array}{c}\text { Estande } \\
\left(\text { planta } 7,2 \mathrm{~m}^{-2}\right)\end{array}$} & \multicolumn{2}{|c|}{ \% de grãos } & \multirow{2}{*}{$\begin{array}{l}\text { Massa média } \\
\text { de } 100 \text { grãos } \\
(\mathrm{g})\end{array}$} & \multirow{2}{*}{$\begin{array}{c}\text { № vagens/ } \\
\text { planta }\end{array}$} & \multirow{2}{*}{ 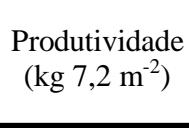 } \\
\hline & D. O. ${ }^{1 /}$ & Transf..$^{2 /}$ & D. $\mathrm{O}$. & Transf..$^{-/}$ & & & \\
\hline 00 & 174,00 & $13,19 \mathrm{~A}$ & 73,28 & $58,82 \mathrm{~A}$ & $34,88 \mathrm{~A}$ & $7,52 \mathrm{~B}$ & $1.311,00 \mathrm{~B}$ \\
\hline $00-17$ & 173,00 & $13,15 \mathrm{~A}$ & 73,57 & $59,09 \mathrm{~A}$ & $34,43 \mathrm{~A}$ & $9,00 \mathrm{AB}$ & $1.590,25 \mathrm{AB}$ \\
\hline $00-31$ & 169,00 & $13,00 \mathrm{~A}$ & 73,91 & $59,32 \mathrm{~A}$ & $35,48 \mathrm{~A}$ & $9,48 \mathrm{~A}$ & $1.640,25 \mathrm{~A}$ \\
\hline $00-45$ & 167,25 & $12,93 \mathrm{~A}$ & 71,62 & $57,82 \mathrm{~A}$ & $36,60 \mathrm{~A}$ & $9,21 \mathrm{AB}$ & $1.589,00 \mathrm{AB}$ \\
\hline $00-59$ & 177,00 & $13,29 \mathrm{~A}$ & 72,92 & $58,65 \mathrm{~A}$ & $36,20 \mathrm{~A}$ & $8,60 \mathrm{AB}$ & $1.605,75 \mathrm{AB}$ \\
\hline $00-73$ & 165,50 & $12,86 \mathrm{~A}$ & 71,80 & $57,93 \mathrm{~A}$ & $35,43 \mathrm{~A}$ & $8,61 \mathrm{AB}$ & $1.469,00 \mathrm{AB}$ \\
\hline $17-31$ & 167,25 & $12,92 \mathrm{~A}$ & 72,49 & $58,37 \mathrm{~A}$ & $34,83 \mathrm{~A}$ & $9,35 \mathrm{~A}$ & $1.562,25 \mathrm{AB}$ \\
\hline $17-45$ & 170,25 & $13,04 \mathrm{~A}$ & 73,03 & $58,71 \mathrm{~A}$ & $37,08 \mathrm{~A}$ & $8,69 \mathrm{AB}$ & $1.550,25 \mathrm{AB}$ \\
\hline $17-59$ & 167,00 & $12,92 \mathrm{~A}$ & 71,96 & $58,03 \mathrm{~A}$ & $35,33 \mathrm{~A}$ & $9,10 \mathrm{AB}$ & $1.519,50 \mathrm{AB}$ \\
\hline $17-73$ & 161,00 & $12,69 \mathrm{~A}$ & 72,33 & $58,26 \mathrm{~A}$ & $36,28 \mathrm{~A}$ & $9,17 \mathrm{AB}$ & $1.496,25 \mathrm{AB}$ \\
\hline $31-45$ & 162,75 & $12,76 \mathrm{~A}$ & 72,79 & $58,56 \mathrm{~A}$ & $36,38 \mathrm{~A}$ & $8,83 \mathrm{AB}$ & $1.498,25 \mathrm{AB}$ \\
\hline $31-59$ & 170,25 & $13,04 \mathrm{~A}$ & 72,68 & $58,48 \mathrm{~A}$ & $35,43 \mathrm{~A}$ & $8,51 \mathrm{AB}$ & $1.452,50 \mathrm{AB}$ \\
\hline $31-73$ & 175,25 & $13,23 \mathrm{~A}$ & 73,14 & $58,79 \mathrm{~A}$ & $33,70 \mathrm{~A}$ & $8,53 \mathrm{AB}$ & $1.499,75 \mathrm{AB}$ \\
\hline $45-59$ & 173,00 & $13,15 \mathrm{~A}$ & 72,05 & $58,08 \mathrm{~A}$ & $37,48 \mathrm{~A}$ & $7,81 \mathrm{AB}$ & $1.400,50 \mathrm{AB}$ \\
\hline $45-73$ & 177,00 & $13,30 \mathrm{~A}$ & 72,56 & $58,41 \mathrm{~A}$ & $35,63 \mathrm{~A}$ & $7,76 \mathrm{AB}$ & $1.399,75 \mathrm{AB}$ \\
\hline $59-73$ & 179,50 & $13,39 \mathrm{~A}$ & 72,13 & $58,14 \mathrm{~A}$ & $33,60 \mathrm{~A}$ & $7,91 \mathrm{AB}$ & $1.371,00 \mathrm{AB}$ \\
\hline 00-colheita & 171,25 & $13,09 \mathrm{~A}$ & 73,19 & $58,82 \mathrm{~A}$ & $35,80 \mathrm{~A}$ & $9,46 \mathrm{~A}$ & $1.651,75 \mathrm{~A}$ \\
\hline $\mathrm{F}$ tratamentos & & $1,09^{\mathrm{ns}}$ & & $0,78^{\mathrm{ns}}$ & $1,59^{\mathrm{ns}}$ & $3,28 * *$ & $2,68 * *$ \\
\hline F blocos & & $1,33^{\mathrm{ns}}$ & & $0,21^{\mathrm{ns}}$ & $0,54^{\mathrm{ns}}$ & $7,26 * *$ & $6,02 * *$ \\
\hline $\mathrm{CV}(\%)$ & & 2,88 & & 1,63 & 4,78 & 7,89 & 7,90 \\
\hline d. m. s. & -- & 0,97 & --- & 2,46 & 4,39 & 1,77 & 307,34 \\
\hline
\end{tabular}

manter-se constante. O autor considera que esse é um mecanismo que auxilia na manutenção da espécie.

Bianco (1978) e Pitelli et al. (1981) observaram efeitos negativos da presença da comunidade infestante na massa média de 100 grãos. Pitelli et al. (1981) comentam que, devido à grande desuniformidade da comunidade infestante na área de cultivo, em termos de composição específica, densidade e distribuição das plantas, os indivíduos de amendoim estão sujeitos às mais diversas condições de sombreamento, competição por nutrientes e água, variações térmicas e hídricas do solo, processos alelopáticos e outros fatores que podem, direta ou indiretamente, alterar o florescimento. Assim, com desuniformidade de florescimento e, conseqüentemente, de frutificação, na colheita podem ser encontradas sementes formadas ao lado de sementes ainda em formação. Com isso, o tamanho médio do grão é reduzido, o que se reflete na massa média de 100 grãos.

No presente caso, D. horizontalis, que era altamente predominante na área, condicionou o comportamento da comunidade e, conseqüentemente, essa grande desuniformidade de condições não existiu. Assim, a maturação possivelmente foi uniforme, explicando os resultados observados.

O número de vagens por planta foi significativamente reduzido pela interferência imposta pelas plantas daninhas nas duas épocas de experimentação (Tabelas 4 e 5). Apenas a testemunha no mato diferiu estatisticamente da testemunha no limpo, apresentando reduções de $20,5 \%$ na cultura "das secas" e 30,4\% na "das águas”. O efeito negativo da interferência 
da comunidade infestante sobre o número de vagens por planta é bastante citado na literatura, sendo constatado por Bianco (1978), Pitelli et al. (1981), Pitelli et al. (1984) e Martins \& Pitelli (1994). Esses autores consideram que o número de vagens por planta parece ser o principal parâmetro produtivo da cultura que é alterado pela interferência das plantas daninhas.

Considerando as testemunhas no limpo, a produtividade de vagens para a cultura "das secas" foi de $2.294 \mathrm{~kg} \mathrm{ha}^{-1} \mathrm{e}$, para a "das águas", de $4.255 \mathrm{~kg} \mathrm{ha}^{-1}$. Nas duas épocas de semeadura, os efeitos das plantas daninhas sobre a produtividade foram significativos (Tabelas 4 e 5), causando reduções de $20,6 \%$ e de $29,2 \%$ na produtividade das culturas "das secas" e "das águas", respectivamente. Para a cultura do período chuvoso, o valor encontrado é próximo ao observado por Barbosa \& Pitelli (1990) e Martins \& Pitelli (1994) e superior ao verificado por Pitelli et al. (1981). Para a cultura "das secas", é bem inferior ao encontrado por Bianco (1978) e Pitelli et al. (1984), provavelmente devido ao pequeno crescimento vegetativo de $D$. horizontalis nessa época de semeadura. As comunidades que infestavam os experimentos desses autores citados tinham maior equilíbrio de participação entre as espécies componentes.

Na análise do teste de Tukey, para a produtividade de vagens na cultura "das secas", pode ser constatado que a testemunha no limpo diferiu significativamente apenas da testemunha no mato (Tabela 4); portanto, o período anterior à interferência (PAI) foi superior a 59 dias. No cultivo "das águas", a testemunha no limpo diferiu, além da testemunha no mato, do tratamento em que o período de controle das plantas daninhas iniciou-se aos 59 dias,

Tabela 5 - Efeitos do período de controle das plantas daninhas sobre o número de plantas na colheita, a porcentagem da massa do grão na vagem, a massa média de 100 grãos, o número de vagens por planta e a produtividade de vagens do amendoim "das águas"

\begin{tabular}{|c|c|c|c|c|c|c|c|}
\hline \multirow{2}{*}{$\begin{array}{l}\text { Período de con- } \\
\text { trole de mato } \\
\quad \text { (dias) }\end{array}$} & \multicolumn{2}{|c|}{$\begin{array}{c}\text { Estande } \\
\left(\text { planta } 7,2 \mathrm{~m}^{-2} \text { ) }\right.\end{array}$} & \multicolumn{2}{|c|}{ \% de grãos } & \multirow{2}{*}{$\begin{array}{c}\text { Massa média } \\
\text { de } 100 \text { grãos } \\
\text { (g) }\end{array}$} & \multirow{2}{*}{$\begin{array}{c}\text { № vagens/ } \\
\text { planta }\end{array}$} & \multirow{2}{*}{ 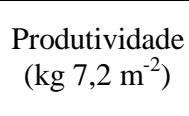 } \\
\hline & D. O..$^{\prime \prime}$ & Transf. $^{2 /}$ & D. O. & Transf..$^{3 /}$ & & & \\
\hline 00 & 178,67 & $13,37 \mathrm{~A}$ & 72,87 & $58,61 \mathrm{~A}$ & $48,90 \mathrm{AB}$ & $9,25 \mathrm{~B}$ & $2.170,00 \mathrm{C}$ \\
\hline $00-17$ & 174,00 & $13,19 \mathrm{~A}$ & 71,79 & $57,92 \mathrm{~A}$ & $47,53 \mathrm{AB}$ & $11,89 \mathrm{AB}$ & $2.653,33 \mathrm{ABC}$ \\
\hline $00-31$ & 170,33 & $13,05 \mathrm{~A}$ & 71,94 & $58,01 \mathrm{~A}$ & $47,50 \mathrm{AB}$ & $12,45 \mathrm{~A}$ & $2.766,67 \mathrm{ABC}$ \\
\hline $00-45$ & 180,67 & $13,44 \mathrm{~A}$ & 72,16 & $58,16 \mathrm{~A}$ & $49,03 \mathrm{AB}$ & $11,51 \mathrm{AB}$ & $2.710,00 \mathrm{ABC}$ \\
\hline $00-59$ & 177,33 & $13,32 \mathrm{~A}$ & 72,15 & $58,15 \mathrm{~A}$ & $48,23 \mathrm{AB}$ & $11,57 \mathrm{AB}$ & $2.723,33 \mathrm{ABC}$ \\
\hline $00-73$ & 172,00 & $13,11 \mathrm{~A}$ & 72,41 & $58,31 \mathrm{~A}$ & $49,30 \mathrm{AB}$ & $12,52 \mathrm{~A}$ & $2.893,33 \mathrm{AB}$ \\
\hline $17-31$ & 168,00 & $12,96 \mathrm{~A}$ & 72,81 & $58,57 \mathrm{~A}$ & $50,67 \mathrm{~A}$ & $12,03 \mathrm{AB}$ & $2.820,00 \mathrm{ABC}$ \\
\hline $17-45$ & 171,00 & $13,08 \mathrm{~A}$ & 72,87 & $58,61 \mathrm{~A}$ & $49,03 \mathrm{AB}$ & $12,45 \mathrm{~A}$ & $2.880,00 \mathrm{AB}$ \\
\hline $17-59$ & 176,33 & $13,28 \mathrm{~A}$ & 72,09 & $58,11 \mathrm{~A}$ & $48,63 \mathrm{AB}$ & $10,84 \mathrm{AB}$ & $2.666,67 \mathrm{ABC}$ \\
\hline $17-73$ & 178,67 & $13,37 \mathrm{~A}$ & 71,93 & $58,01 \mathrm{~A}$ & $48,97 \mathrm{AB}$ & $10,60 \mathrm{AB}$ & $2.566,67 \mathrm{ABC}$ \\
\hline $31-45$ & 174,00 & $13,19 \mathrm{~A}$ & 72,23 & $58,20 \mathrm{~A}$ & $48,60 \mathrm{AB}$ & $11,78 \mathrm{AB}$ & $2.766,67 \mathrm{ABC}$ \\
\hline $31-59$ & 165,33 & $12,86 \mathrm{~A}$ & 72,10 & $58,12 \mathrm{~A}$ & $47,47 \mathrm{AB}$ & $12,70 \mathrm{~A}$ & $2.853,33 \mathrm{ABC}$ \\
\hline $31-73$ & 175,67 & $13,25 \mathrm{~A}$ & 71,96 & $58,03 \mathrm{~A}$ & $48,57 \mathrm{AB}$ & $11,42 \mathrm{AB}$ & $2.713,33 \mathrm{ABC}$ \\
\hline $45-59$ & 170,67 & $13,06 \mathrm{~A}$ & 72,02 & $58,07 \mathrm{~A}$ & $46,70 \mathrm{~B}$ & $10,81 \mathrm{AB}$ & $2.383,33 \mathrm{ABC}$ \\
\hline $45-73$ & 172,67 & $13,14 \mathrm{~A}$ & 71,40 & $57,67 \mathrm{~A}$ & $47,33 \mathrm{AB}$ & $10,51 \mathrm{AB}$ & $2.380,00 \mathrm{ABC}$ \\
\hline $59-73$ & 169,33 & $13,01 \mathrm{~A}$ & 72,17 & $58,16 \mathrm{~A}$ & $47,80 \mathrm{AB}$ & $10,52 \mathrm{AB}$ & $2.330,00 \mathrm{BC}$ \\
\hline 00-colheita & 172,67 & $13,14 \mathrm{~A}$ & 72,41 & $58,32 \mathrm{~A}$ & $48,93 \mathrm{AB}$ & $13,29 \mathrm{~A}$ & $3.063,33 \mathrm{~A}$ \\
\hline $\mathrm{F}$ tratamentos & & $1,54^{\mathrm{ns}}$ & & $1,13^{\mathrm{ns}}$ & $2,25 *$ & $3,12 * *$ & $3,04 * *$ \\
\hline F blocos & & $1,48^{\mathrm{ns}}$ & & $4,12 *$ & $0,49^{\mathrm{ns}}$ & $3,59 *$ & $5,79 * *$ \\
\hline $\mathrm{CV}(\%)$ & & 1,67 & & 0,70 & 2,27 & 8,69 & 8,70 \\
\hline d. m. s. & -- & 0,67 & $-\cdots$ & 1,24 & 3,37 & 3,07 & 709,97 \\
\hline
\end{tabular}

${ }^{1 /}$ Dados originais. ${ }^{2 /}$ Transformação em raiz de (x). ${ }^{3 /}$ Transformação em arc seno da raiz de (x).

${ }^{\text {ns }}$ Não-significativo. * Significativo a $5 \%$ de probabilidade. ${ }^{*}$ Significativo a $1 \%$ de probabilidade. Médias acompanhadas de mesma letra não diferem estatisticamente entre si (Tukey, 5\%). 
indicando que o término do PAI está localizado entre 45 e 59 dias (Tabela 5). Esses resultados são parecidos com os verificados por Pitelli et al. (1981) e Pitelli et al. (1984), que determinaram o PAI ao redor de 56 dias, e concordam com Bianco (1978), Pitelli et al. (1981) e Pitelli et al. (1984), os quais sugerem que a época crítica da interferência das plantas daninhas inicia-se por ocasião da formação do fruto e do enchimento dos grãos.

Nas duas épocas experimentais, não houve diferença estatística entre a testemunha no limpo e o tratamento em que o controle das plantas daninhas abrangeu o período da emergência até os 17 dias do ciclo, indicando que o período total de prevenção da interferência é igual ou inferior a 17 dias (Tabelas $4 \mathrm{e}$ 5). Esse resultado é coerente com os verificados por Pitelli et al. (1981), Barbosa \& Pitelli (1990), Martins \& Pitelli (1994) e Kasai et al. (1997), podendo ser explicado pela emergência de poucas plantas depois da primeira quinzena do ciclo da cultura.

Pelos resultados, em ambas as épocas de semeadura, uma operação de controle entre 17 e 45 dias preveniria a interferência das plantas daninhas na cultura do amendoim, pois seria realizada após ou no final do PTPI e antes do término do PAI.

\section{LITERATURA CITADA}

BARBOSA, L. M.; PITELLI, R. A. Estudos sobre períodos de interferência de plantas daninhas na produtividade do amendoinzeiro (Arachis Hypogaea L.). Hoehnea, v. 17, n. 2, p. 33-41, 1990.

BHAN, V. M.; SINGH, M.; MAURYA, R. E. Crop weed competition studies in groundnuts. Ind. Weed Sci., v. 3, p. 32-36, 1971.

BIANCO, S. Matocompetição em amendoim "das secas" sob diferentes condições de adubação. Jaboticabal: Universidade Estadual Paulista, 1978. 66 p. Monografia (Graduação em Agronomia) - Universidade Estadual Paulista, 1978.

BUCHANAN, G. A. et al. Competition of Florida beggarweed and sicklepod with peanut. II. Effects of cultivation weeds and SADH. Weed Sci., v. 24, n. 1, p. 29-39, 1976.
CHAMBLEE, R. W.; THOMPSON JR, L.; COBLE, H. D. Interference of broadleaf signalgrass (Brachiaria platyphylla) in peanut (Arachis hypogaea L.). Weed Sci., v. 30, n. 1, p. 45-49, 1982.

DAJOZ, R. Ecologia geral. Petrópolis: Vozes, 1983. 472 p.

FEAKIN, S. D. Pest control in groundnuts. 3.ed. London: Center for Overseas Pest Research, 1973. 197 p.

KASAI, F. S. et al. Efeitos dos períodos de competição do mato na cultura do amendoim: I. Safra da seca de 1988.

Bragantia, v. 56, n. 2, p. 323-331, 1997.

KISSMANN, K. G. Plantas infestantes e nocivas. 2.ed. São Paulo: Basf, 1997. v. 1. 825 p.

LORENZI, H. Plantas daninhas do Brasil. 2.ed. Nova Odessa: Plantarum, 1991. 440 p.

MARTINS, D.; PITELLI, R. A. Interferência das plantas daninhas na cultura do amendoim das águas: efeitos de espaçamentos, variedades e períodos de convivência. Planta Daninha, v. 12, n. 2, p. 87-92, 1994.

PACHECO, R. P. B. Duração do período de competição de plantas invasoras com a cultura do amendoim-da-seca (Arachis hypogaea L.). Vegetalia, v. 3, p. 1-11, 1980.

PITELLI, R. A. Efeitos do período de competição das plantas daninhas sobre a produtividade do amendoim (Arachis hypogaea L.) e o teor de macronutrientes em suas sementes. Piracicaba: Escola Superior de Agricultura "Luiz de Queiroz", 1980. 89 p. Dissertação (Mestrado em Nutrição de Plantas) - Escola Superior de Agricultura "Luiz de Queiroz", 1980.

PITELLI, R. A. Interferência das plantas daninhas em culturas agrícolas. Inf. Agropec., v. 11, n. 129, p. 16-27, 1985.

PITELLI, R. A.; FERRAZ, E. C.; DE MARINIS, G. Efeito do período de matocompetição sobre a produtividade do amendoim (Arachis hypogaea L.). Planta Daninha, v. 4, n. 2, p. 110-119, 1981.

PITELLI, R. A. et al. Efeitos de períodos de convivência das plantas daninhas sobre a produtividade da cultura do amendoim das secas. Planta Daninha, v. 7, n. 1, p. 58-64, 1984.

ROYAL, S. S. et al. Influence of broadleaf weeds on chloorthalonil deposition, foliar disease incidence, and peanut (Arachis hypogaeae) yield. Weed Technol., v. 11, n.1, p. 51-58, 1997. 